\title{
無電解法による垂直磁化膜用軟質磁性下地層の作製
}

\author{
松田均*, 鷹 野 \\ 修*

\section{Preparation of Soft Magnetic Undercoating Layer for Perpendicular Recording Media by Electroless Plating}

Hitoshi MATSUDA* and Osamu TAKANO*

\begin{abstract}
A soft magnetic undercoating layer for perpendicular recording media was prepared by electroless plating method, and the most optimum plating conditions were investigated.

The iron content of nickel-iron-phosphorus films varied from 0 to $18 \%$ with the ferrous sulfate concentration in the plating solution. The addition of iron to nickel-phosphorus plating film decreased their coercive force and increased squareness. Film deposited from the most optimum plating solution exhibited coercive force of $1.0 \mathrm{Oe}$ and squareness of 0.95 and showed strong (111) plane orientation, which improved the anisotropy of perpendicularly magnetized film.
\end{abstract}

Key Words : Electroless Plating, Perpendicular Magnetic Recording, Soft Magnetic layer, Undercoating layer

\section{1. 緒言}

スパッタ法による $\mathrm{Co}-\mathrm{Cr}$ 垂直磁化膜では, $\mathrm{Ti} \mathrm{i}^{1)}$ $\mathrm{Ge}^{2)}$ 膜を下地として施した場合，結晶の垂直配向性が 向上するとされている。また, 著者らは無電解コバルト 系垂直磁化膜に执いて，その下地として，（111）面配 向の強い無電解ニッケル系皮膜を用いるとき，エピタキ シャル成長によって $\alpha$ Co (002) 面が配向しやすくなり, その結果, 磁性層の結晶および磁気的な垂直異方性が攵 善されることを前報 ${ }^{3)}$ で報告した。

一方, 垂直磁気記録媒体の記録再生過程において, 高 透磁率の軟質磁性膜で裏打ちされた二層膜媒体を構成す ると，下地層がヘッドの一部として動き，その記録感度 および再生出力が大幅に向上することが知られてい る4),5)。そこで，本報では，良好な軟質磁性を示すとと もに（111）面配向の強い下地層を無電解法によって作 製すれば，前述の目的を同時に達成できるものと考え， 下地めっきの作製条件を検討したところ良好な結果が得 られたので以下に報告する。

\section{2. 実 験 方 法}

素地には片面にPdをスパッタしたポリイミドフィル 么（侏東レ製，厚 $25 \mu \mathrm{m}$ )を用い，下地めっき浴として 表 1-(a)に示した無電解 $\mathrm{Ni}-\mathrm{Fe}-\mathrm{P}$ 浴を選定し, 硫酸 ニッケルおよび硫酸第一鉄濃度をそれぞれ変化させて下

* 姫路工業大学（テ671-22 兵庫県姫路市書写2167）

Himeji Institute of Technology (2167, Shosha, Himeji-shi, Hyogo 671-22)
地めっきとしての適否を検討した。また，垂直磁化膜作 製には既報 ${ }^{6)}$ の酒石酸ナトリウムを錯化剂とした無電解 Co-Ni-Mn-Re-P 浴（変 1 - ( b ) ) を使用した。下地めっ き層および垂直磁化膜の皮膜構造はそれぞれX線回折図 およびCo（002）面に打けるロッキング曲線より判定し た。下地めっき層の皮膜磁性は軟質磁性膜用ヒストロス コープ（日本科学ェンジニアリング制 DT 105）で外 部磁場 50 Oe をかけて測定した。また，皮膜組成はブ

Table 1 Bath compositions and plating conditions of undercoating and perpendular magnetic layer.

(a)

\begin{tabular}{|c|c|c|}
\hline $\mathrm{NiSO}_{4}$ & $0.05-0.20$ & $(\mathrm{~mol} / \mathrm{L})$ \\
\hline $\mathrm{FeSO}_{4}$ & $0-0.17$ & $(\mathrm{~mol} / \mathrm{L})$ \\
\hline $\mathrm{NaH}_{2} \mathrm{PO}_{2}$ & 0.10 & $(\mathrm{~mol} / \mathrm{L})$ \\
\hline $\mathrm{NaC}_{6} \mathrm{H}_{5} \mathrm{O}_{7}$ & 0.20 & $(\mathrm{~mol} / \mathrm{L})$ \\
\hline$\left(\mathrm{NH}_{4}\right)_{2} \mathrm{SO}_{4}$ & 0.20 & $(\mathrm{~mol} / \mathrm{L})$ \\
\hline $\mathrm{pH}$ & \multicolumn{2}{|c|}{ 10. 2 (with $\mathrm{NaOH}$ ) } \\
\hline Temp. & \multicolumn{2}{|c|}{$353 \pm 1 \mathrm{~K}$} \\
\hline
\end{tabular}

\begin{tabular}{|c|c|c|}
\hline $\mathrm{CoSO}_{4}$ & 0.06 & $(\mathrm{~mol} / \mathrm{L})$ \\
\hline $\mathrm{NiSO}_{4}$ & 0.04 & $(\mathrm{~mol} / \mathrm{L})$ \\
\hline $\mathrm{MnSO}_{4}$ & 0.03 & $(\mathrm{~mol} / \mathrm{L})$ \\
\hline $\mathrm{NH}_{4} \mathrm{ReO}_{4}$ & 0.007 & $(\mathrm{~mol} / \mathrm{L})$ \\
\hline $\mathrm{NaH}_{2} \mathrm{PO}_{2}$ & 0.20 & $(\mathrm{~mol} / \mathrm{L})$ \\
\hline $\mathrm{Na}_{2} \mathrm{C}_{4} \mathrm{H}_{4} \mathrm{O}_{6}$ & 0.50 & $(\mathrm{~mol} / \mathrm{L})$ \\
\hline$\left(\mathrm{NH}_{4}\right)_{2} \mathrm{SO}_{4}$ & 0.50 & $(\mathrm{~mol} / \mathrm{L})$ \\
\hline $\mathrm{pH}$ & \multicolumn{2}{|c|}{9.2 (with $\mathrm{NH}_{4} \mathrm{OH}$ ) } \\
\hline Temp. & \multicolumn{2}{|c|}{$353 \pm 1 \mathrm{~K}$} \\
\hline
\end{tabular}


ラズマ発光分光分析装置（セイコー電子峨製 SPS1100ににより測定した。

\section{3. 実験結果および考察}

\section{1 下地めっきの析出挙動}

表 1-（a ）に示す基本浴において浴中の硫酸ニッケル または硫酸第一鉄濃度を変化させた場合の析出速度に対 する影響を調べた結果を図 1 に示した。図1より， $\mathrm{NiSO}_{4}$ 濃度が高いほど析出速度はより大きいが，0.20 $\mathrm{mol} / \mathrm{L}$ 以上の添加によって浴が不安定化することが分 かる。一方, $\mathrm{FeSO}_{4}$ 濃度の增加によって析出速度はほ とんど変化しないが, 濃度が $0.1 \mathrm{~mol} / \mathrm{L}$ 以上になると $\mathrm{Fe}(\mathrm{OH})_{2}$ とみられる淡緑色沈殿が認められ同時に浴の 不安定化を招く。また， $\mathrm{NiSO}_{4}$ 濃度の高い浴ほど
$\mathrm{FeSO}_{4}$ の添加による浴の不安定化が起こりやすい傾向 があり，結局，適当な両金属塩の合計濃度は $0.25 \mathrm{~mol} /$ L 以下の範囲に限定される。

皮膜表面の光沢性は，浴中への $\mathrm{FeSO}_{4}$ 添加によって ほとんど変化せず良好な金属光沢を示した。また，ポリ イミド素地上にめっきした Ni-P 皮膜に执いては, 膜厚 $3 \mu \mathrm{m}$ 以上ではクラックを生じ，はく離する傾向がみら れたが，このような現象は浴中への $\mathrm{FeSO}_{4}$ 添加量が増 すにつれ減少した。これは $\mathrm{Fe}$ 共析に伴い皮膜中の残留 応力が減少するためと推測される。

皮膜組成については，図２に示すように，浴中の $\mathrm{FeSO}_{4}$ 濃度が増すにつれて，皮膜中の $\mathrm{Fe}$ 含有率は直線 的に增加し, $\mathrm{FeSO}_{4} 0.15 \mathrm{~mol} / \mathrm{L}$ 濃度の浴からは約 $15 \%$ の共析を示した。一方， $\mathrm{P}$ 含有率は， $\mathrm{FeSO}_{4}$ 無添加浴

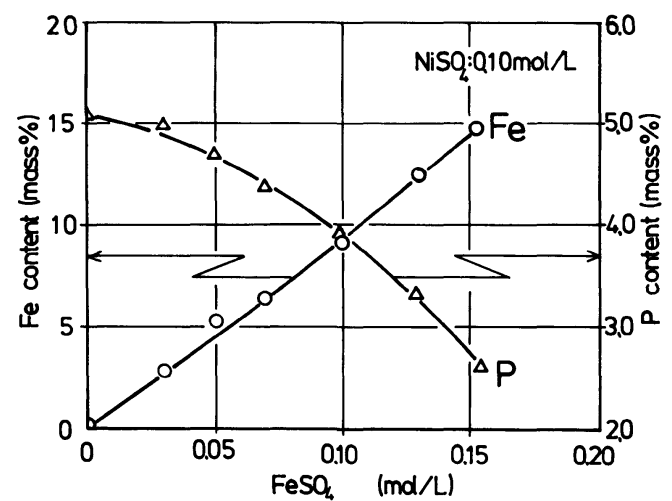

Fig. 2 Effect of $\mathrm{FeSO}_{4}$ concentration on compositions of $\mathrm{Ni}-\mathrm{Fe}-\mathrm{P}$ films
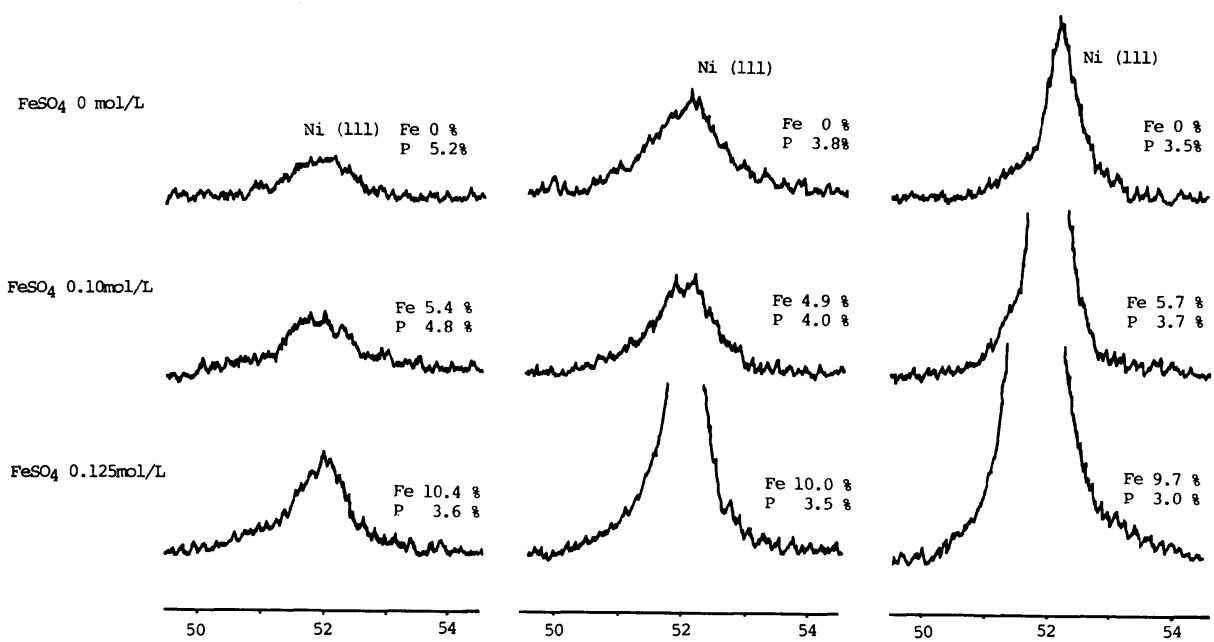

$2 \theta$ (degrees)

$\mathrm{CO} \mathrm{Ka} \quad 30 \mathrm{kv}$ 1OmA

Fig. $3 \mathrm{X}$-ray diffraction patterns of electroless Ni-Fe-P films

Film thickness $2.0 \mu \mathrm{m}$ 

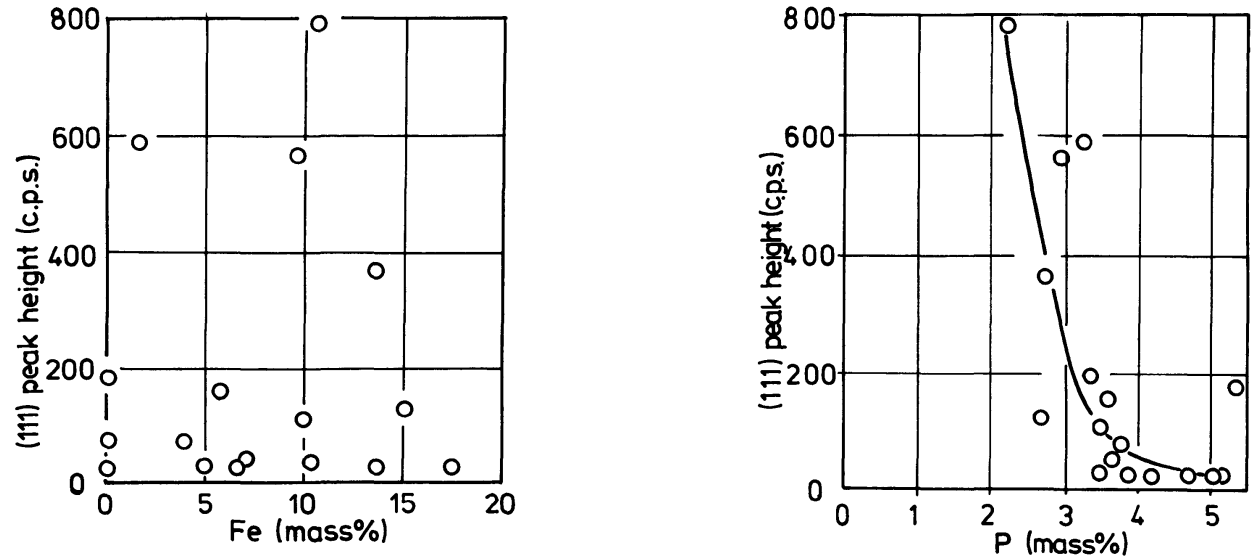

Fig. 4 Relation between film compositions and $\mathrm{Ni}(111)$ peak height of $\mathrm{Ni}-\mathrm{Fe}-\mathrm{P}$ films.

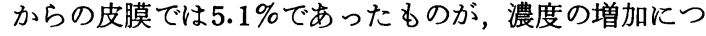
れ逆に低下し， $0.15 \mathrm{~mol} / \mathrm{L}$ 添加の場合， $2.6 \%$ と半減す る。

\section{2 皮膜構造}

表 1 に示した基本浴中の硫酸ニッケルおよび硫酸第一 鉄濃度を变化させてめっきした各 $\mathrm{Ni}-\mathrm{Fe}-\mathrm{P}$ 皮膜の構造 をX線回折法によって調べ，その結果を図 3 に示した。 图 3 より, $\mathrm{NiSO}_{4}$ 濃度 $0.075 \mathrm{~mol} / \mathrm{L}$ の浴の場合, $\mathrm{FeSO}_{4}$ 無添加の浴からの皮膜ではブロードパターンを 示しているが, $\mathrm{FeSO}_{4}$ 濃度が増すにつれて次第に明瞭 な（111）面回折ピークがみられるようになる。同様の 傾向は $\mathrm{NiSO}_{4}$ 濃度を変化させた各浴からの皮膜でも認 められ, $\mathrm{FeSO}_{4}$ 濃度一定では, $\mathrm{NiSO}_{4}$ 濃度が高いはど 結晶性が良くなっている。

以上の結果から皮膜中の $\mathrm{Fe}$ または $\mathrm{P}$ 含有率と皮膜構 造の関係を整理し図 4 に示した。困より（111）面から の回折線強度と $\mathrm{Fe}$ 含有率との間には関連性は認めにく いが，P含有率との間には相関性が認められ，P含有率 が低い皮膜ほど（111）回折線強度は強く結晶性が良い ことが分かる。このことは， $\mathrm{FeSO}_{4}$ 添加により $\mathrm{P}$ 含有 率が低下寸るという結果（図 2 ）と考光合わせると，上 記の結晶性の向上は, $\mathrm{FeSO}_{4}$ 添加による皮膜中の $\mathrm{Fe}$ 含 有率の増加よりむしろ P 含有率 の低下に起因している ものと考元られるそこで，基本浴組成に打ける $\mathrm{FeSO}_{4}$ 濃度以外の他の条件を変化させて皮膜中の $\mathrm{P}$ 含 有率の減少をはかったが, 結局, $\mathrm{FeSO}_{4}$ の添加が最も 効果的であった。

以上のように，本研究の目的の一つである（111）面 の配向性を高めるためには，P含有率を $3 \%$ 以下の低い レベルに押さえる必要があり， $\mathrm{FeSO}_{4}$ 添加がこの目的 に対し有効であることが判明した。

\section{3 下地めっきの磁気特性}

次に, $\mathrm{NiSO}_{4}$ 濃度の異なる各浴中へ $\mathrm{FeSO}_{4}$ を添加し， その濃度の析出皮膜磁性への影響を調べた結果を図 5 に


Fig. 5 Effect of $\mathrm{FeSO}_{4}$ concentration on magnetic properties of $\mathrm{Ni}-\mathrm{Fe}-\mathrm{P}$ films.

示した。な拉，測定膜厚は $2.0 \mu \mathrm{m}$ である。図より，保 磁力 $(\mathrm{Hc})$ に関しては，まず， $\mathrm{Ni}-\mathrm{P}$ 皮膜では $\mathrm{NiSO}_{4}$ 濃 度に依存して $10 \sim 30$ Oe を示しているが，浴中の $\mathrm{FeSO}_{4}$ 濃度が増すと約 $1 \mathrm{Oe}$ まで低下する。また，浴中 の $\mathrm{NiSO}_{4}$ 濃度が高い浴ほど低 $\mathrm{FeSO}_{4}$ 濃度の浴に括いて も析出皮膜の保磁力は低下することが分かる。

一方, 角形比 $(\mathrm{Br} / \mathrm{Bs})$ 飞ついては, $\mathrm{NiSO}_{4}$ 濃度 0.15 $\mathrm{mol} / \mathrm{L}$ の浴においては， $\mathrm{FeSO}_{4}$ の添加量を增しても皮 膜の $\mathrm{Br} / \mathrm{Bs}$ 值は0.7 0.8の範囲で変化は少ないが, $\mathrm{NiSO}_{4}$ 濃度が $0.05 \sim 0.125 \mathrm{~mol} / \mathrm{L}$ の各浴では, $\mathrm{FeSO}_{4}$ 濃度が増すにつれ角形比は向上しており，最高値は0.95 に達する。

以上の結果から，皮膜中の $\mathrm{Fe}$ または $\mathrm{P}$ 含有率と皮膜 の磁気特性との関係を整理して図 6 に示す。図より，保 

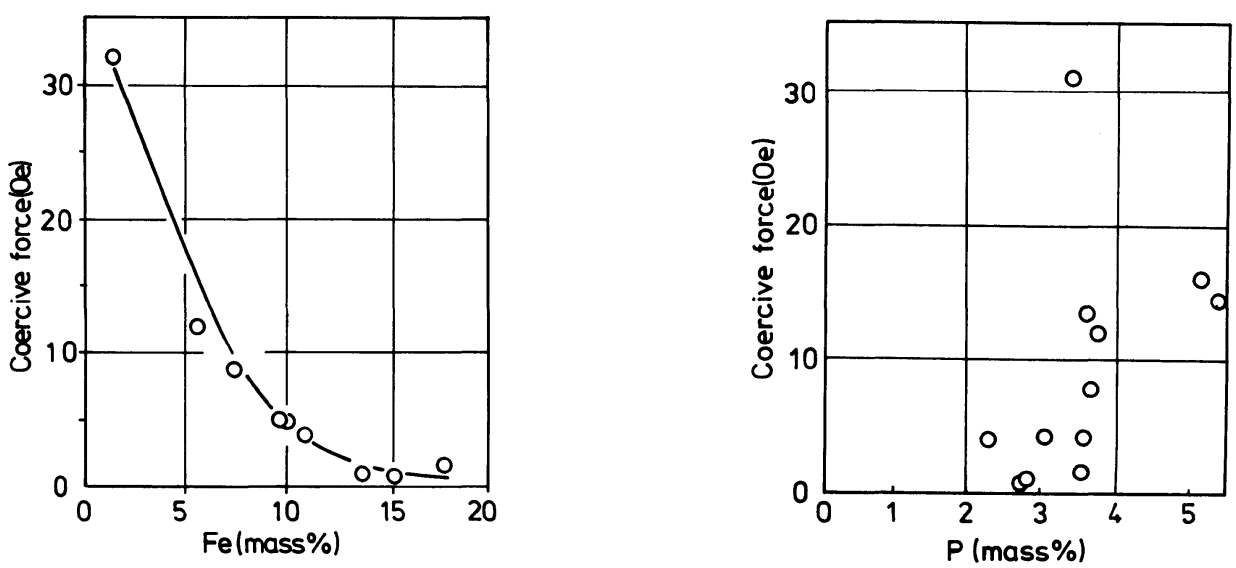

Fig. 6 Relation between film compositions and magnetic properties of $\mathrm{Ni}-\mathrm{Fe}-\mathrm{P}$ films.

磁力と $\mathrm{P}$ 含有率との間に相関性は見い出しにくいが, $\mathrm{Fe}$ 含有率との間には相関性が認められ, $\mathrm{Hc}$ は Fe 含有 率の增加ととも低下して扣り, $\mathrm{Fe}$ 含有率 $13 \%$ 以上の 皮膜では, ほぼ1 Oe となっている。また,この場合, 面内での Hc の方向依存性は認められなかった。

一般に，軟質磁性材料の磁気特性（保磁力）に影響す る因子としては, 磁歪定数, 結晶異方性定数 $\mathrm{K}_{1}$, 非磁性 析出物量, 内部応力等が挙げられている7゙。無電解 $\mathrm{Ni}$ $\mathrm{P}$ 皮膜中に $\mathrm{Fe}$ を共析させることにより良好な軟質磁性 膜が得られた理由として，まず，皮膜組成の点では，ハ 一マロイ組成 (Ni $78 \%, F e 22 \%)$ 飞比較的近く，合 金組成に支配されやすい磁需定数，結晶磁気異方性定数 $\mathrm{K}_{1}$ がパーマロイ合金と同様に小さくなっているものと みられる。また，皮膜中の $\mathrm{P}$ 含有率が $\mathrm{Fe}$ の共析によっ て大幅に減少するため, 磁壁をトラップし保磁力を高め る要因とみられる非磁性のリン化物が減少すること，さ らに，磁気弾性エネルギーに関連して，Fe 共析によっ て内部応力が低下している点も保磁力の減少に寄与して いるものとみられる。

\section{4 好適浴条件}

以上のように, Ni (111) 面配向性と軟質磁性とを兼 備した下地めっきの作製に対して, 皮膜中への $\mathrm{Fe}$ 共析 が効果的であることが分かった。しかし，浴中への $\mathrm{FeSO}_{4}$ 添加は, 前述のように, 浴の不安定化を招くた め，この点を考慮して，好適浴条件を決定する必要があ る。図 7 は, $\mathrm{NiSO}_{4}$ 打よび $\mathrm{FeSO}_{4}$ 濃度と皮膜特性並び に浴の安定性をまとめて示したものである。図 7 より, 皮膜結晶の (111) 面配向が強く, かつ保磁力が $5 \mathrm{Oe}$ 以下で浴の不安定化が起こらない金属塩濃度範囲は眓中 の斜線部分であり，比較的せまいことが分かる。このう ち，最も好適と考えられる浴条件は，表 1 で示した基本 浴条件下で金属塩濃度を $\mathrm{NiSO}_{4} 0.10 \mathrm{~mol} / \mathrm{L}, \mathrm{FeSO}_{4}$ $0.13 \mathrm{~mol} / \mathrm{L}$ としたものである。この浴条件下で析出さ せた皮膜（膜厚 $2.0 \mu \mathrm{m}$ ) のB-H ループは, 図8 に示す

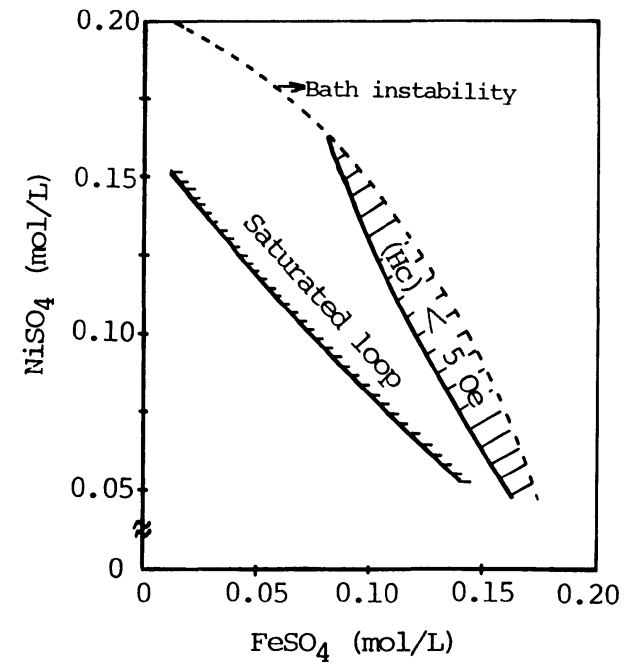

Fig. 7 Preferable metal ion concentration for softmagnetic films

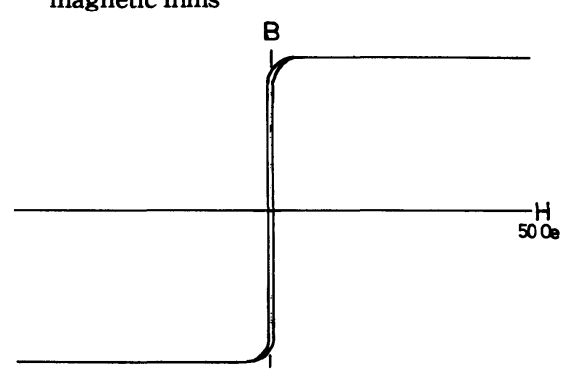

Fig. 8 B-H loop of electroless Ni-Fe-P film.

ように, 保磁力 $1 \mathrm{Oe}$, 角形比 0.95 の良好な軟質磁性膜で ある。

次に，同皮膜を下地めっきとして垂直磁性層を析出さ せ，その構造および皮膜磁性を検討した。その結果を図 9 に示した。なお，この場合，実際の使用条件に近づけ るため, 下地層膜厚, $0.2 \mu \mathrm{m}$, 磁性層膜厚 $0.6 \mu \mathrm{m}$ で測 定した。このうち，下地層については，上述の検討の際 の $2 \mu \mathrm{m}$ 膜厚の皮膜とは組成および構造に顕著な差は認 



Fig. 9 Rocking curve and M-H loop of Co-Ni-Mn-Re-P film.

められなかった。図より,まず, ロッキング曲線の半価 幅 $\left(\Delta \theta_{50}\right)$ 飞関しては, 下地めっきなしの場合，前報で 報告したように, $\Delta \theta_{50}$ は $14^{\circ}$ (膜厚 $2.0 \mu \mathrm{m}$ ) であるのに 対し, 本皮膜を下地めっきとして施すと磁性層膜厚が薄 いにもかかわらず，9.0と低い值を示し，結晶の垂直異 方性が大きく改善されることが分かる。また，M-H ル 一プからは，膜面に垂直方向に測定した場合の保磁力， 角形比共に高く，磁気的な垂直異方性も高いことがうか がえる。このように, 今回開発した無電解 Ni-Fe-P 下 地めっきは垂直磁化膜の特性改善にも寄与することが分 かった。

\section{4. 結}

言

垂直磁気記録媒体作製のための軟質磁性下地めっきと して，無電解ニッケル一鉄ーリン合金めっきの析出条件と 皮膜構造および磁性との関係を検討し，次の結論を得た。

1)本合金浴において，浴中の硫酸第一鉄濃度によって 析出速度はほとんど变化しない。また，浴の安定性は金 属塩濃度が増すにつれ低下するが, $\mathrm{NiSO}_{4}$ と $\mathrm{FeSO}_{4}$ の 合計濃度が $0.25 \mathrm{~mol} / \mathrm{L}$ 以下では安定性は良好である。

2)合金皮膜中の $\mathrm{Fe}$ 含有率は，浴中の $\mathrm{FeSO}_{4}$ 濃度の 上昇とともに増加し，最高 $18 \%$ まで共析した。一方， $\mathrm{P}$ 含有率は， $\mathrm{FeSO}_{4}$ 濃度が増すにつれ低下する傾向がみ られた。

3)浴中の $\mathrm{FeSO}_{4}$ 濃度の増加に伴い析出皮膜中の $\mathrm{P}$ 含 有率が低下し，その結果，皮膜の結晶性が良好となり， $\mathrm{P}$ 含有率 $3 \%$ 以下のとき，強い（111）配向が認められ た。
4)皮膜中の $\mathrm{Fe}$ 含有率の増加とともに，皮膜の保磁力 は低下し, $\mathrm{Fe}$ 含有率 $13 \%$ 以上の皮膜では, 保磁力 1 Oe, 角形比 0.95 の軟質磁性膜が得られた。

5)浴の安定性，析出皮膜の結晶構造 (配向性), 磁 気特性を考虑すると，好適金属塩濃度は， $\mathrm{NiSO}_{4} 0.10$ $\mathrm{mol} / \mathrm{L}, \mathrm{FeSO}_{4} 0.13 \mathrm{~mol} / \mathrm{L}$ となり, 同浴から得られ皮 膜を下地めっきとして施した場合，垂直磁化膜の構造抽 よび磁気的な垂直異方性は大きく改善された。

（昭和61年10月，金属表面技術協会第74回講演大会にて 発表)

(1987-2-6 受理)

本論文中の非SI単位のSI単位に対する換算表

\begin{tabular}{c|c|c}
\hline 量 & 単位記号 & SI単位による值 \\
\hline 磁界の强さ & Oe & $10 \mathrm{e}$ は $(1000 / 4 \pi) \mathrm{A} / \mathrm{m}$ に相当 \\
\hline
\end{tabular}

\section{文献}

1）杉田龍二, 東間清和, 本田和義, 南部太郎, 坂本洋一; 電 子通信学会, 磁気記録研究会資料, MR 84-51 (1984)

2) M. Futamoto ; Intermag. Conf., DB-1 (1985)

3）松田 均, 鷹野 修; 金属表面技術, 37, 753 (1986)

4) S. Iwasaki, K. Ouchi ; IEEE Trans. Mag., MAG-15, 1456 (1979)

5）大内一弘, 岩崎俊一; 応用磁気学会第23回研究会資料, p .51 (1983)

6) O. Takano, H. Matsuda ; Met. Fin., 84, 60 (1986)

7）たとえば，岩間義郎；磁性材料入門, p.8（金属学会, 1986) 